\title{
Evaluation of a Pilot Project to Combat Community Malnutrition in the Health District of Korhogo, Côte d'Ivoire
}

\author{
Coulibaly Amed" ${ }^{1, *}$, Coulibaly Aboubakary ${ }^{2}$, Egnon Vivien Kouakou ${ }^{3}$, Ake-Assi Marie-Hélène ${ }^{4}$ \\ ${ }^{1}$ Department of Public Health and Biostatistics, Faculty of Medical Sciences, University Félix Houphouët-Boigny (UFHB), Abidjan, Côte \\ d'Ivoire \\ ${ }^{2}$ Department of Health and Nutrition, Action Against Hunger, Yaoundé, Cameroon \\ ${ }^{3}$ Department of Nutrition and Pharmacology, Faculty of Biosciences, University Félix Houphouët-Boigny (UFHB), Abidjan, Côte d'Ivoire \\ ${ }^{4}$ Department of Mother-Child, Medical Pediatrics Unit Yopougon University Hospital Center, Abidjan, Côted'Ivoire
}

\section{Email address:}

coulibalyamed_10@yahoo.fr (C. Amed)

*Corresponding author

\section{To cite this article:}

Coulibaly Amed, Coulibaly Aboubakary, Egnon Vivien Kouakou, Ake-Assi Marie-Hélène. Evaluation of a Pilot Project to Combat Community Malnutrition in the Health District of Korhogo, Côte d'Ivoire. American Journal of Health Research.

Vol. 6, No. 1, 2018, pp. 1-5. doi: 10.11648/j.ajhr.20180601.11

Received: November 24, 2017; Accepted: November 28, 2017; Published: January 2, 2018

\begin{abstract}
In Côte d'Ivoire, to combat community malnutrition, the country has opted for the Learning and Nutritional Rehabilitation Center (FARN). Before establishing these centers, a pilot phase was initiated in the Korhogo Health District. The objective of this study was to assess the impact of this intervention in the community. This was a retrospective and prospective cross-sectional study that targeted children aged 6 to 59 months and their mothers. The variables studied were the prevalence of acute malnutrition, the nutritional status of discharged children cared in the community, and the change in mothers' behavior. The results show a significant reduction in the prevalence of malnutrition among 6- to 59-month-old children from $9.7 \%$ to $6.2 \%$, a cure rate of $89.1 \%$ for children discharged and a consolidation rate of a good nutritional status at $85.4 \%$ at 3 months in these same children. Among mothers benefiting from FARN, there was a change in behavior favorable to good nutritional practices compared to non-beneficiary mothers. In view of these results, FARNs prove to be an effective approach to fighting malnutrition in Côte d'Ivoire. Extending this approach to the entire national territory is therefore essential.
\end{abstract}

Keywords: Malnutrition, Prevention, Community, Côte d'Ivoire

\section{Introduction}

Like many developing countries, Côte d'Ivoire is confronted with the problem of malnutrition. High prevalence of acute malnutrition above $10 \%$ in the northern and western regions of the country was confirmed by the 2008 SMART survey [1]. To face this situation, a response plan was initiated and allowed the implementation of programs to combat malnutrition. In the short term, this was about the establishment of units for the management of malnutrition in health facilities, such as the Nutritional Therapeutic Units (UNT), the Ambulatory Therapeutic Nutritional Units (UNTA), the Nutrition Centers Supplements (CNS), and in the long term to strengthen the prevention of malnutrition.
After five years of implementation of this response and the functioning of these structures, the malnutrition rate has fallen sharply between $4.7 \%$ and $7.7 \%$ in these regions [2]. Despite this considerable drop in the malnutrition rate, the situation is still worrying in these areas, as access to health facilities is still problematic; all of which can help to destroy the efforts already made and slow down the evolution of the fight against this disease if a new strategy is not found. It is in this view that the country has embarked on a vision of combating malnutrition in communities with the involvement of communities.

In order to achieve its objectives, Learning and Nutritional Rehabilitation Centers (FARN) have been set up 
as an approach [3]. The aim of this approach is to ensure the nutritional rehabilitation of children under 5 years of age suffering from Moderate Acute Malnutrition (MAM) from local foods and to prevent malnutrition in healthy children through the adoption of good behavior. Before the extension of this new activity throughout the national territory, a pilot phase of the project was carried out in the health district of Korhogo from March 2010 to November 2011.

In view of the urgency and the importance of the objectives to be achieved in the fight against malnutrition among children under 5 years of age in Côte d'Ivoire, it was important to assess the impact of the FARN approach on the nutritional status of children under 5 and on the behavior of mothers 6 months after the start of the pilot phase, in order to justify its reproducibility as early as possible.

The objectives of this study were to: (i) compare the prevalence of malnutrition at the beginning and at the midpoint of the project; (ii) to determine the level of consolidation of the nutritional rehabilitation of children from 6 to 59 months discharged (discharged) and followed at home; (iii) compare the level of good feeding behavior of the beneficiary mothers and the non-beneficiary mothers.

\section{Materials and Method}

\subsection{Description of FARN}

The FARN is a community-based program to combat acute malnutrition in children under five, based on the fundamental principle of rehabilitation of all Moderate Acute Malnutrition (MAM) children identified in the community from recipes made with locally available foods. FARN use positive models (or positive deviance) to change behaviors. They bring the other mothers into contact with a "mother of light", and she is expected to share her experience and know-how in demonstrating that it is possible to raise healthy children with limited means. FARN have three closely related objectives:

1. Rehabilitating children suffering from acute malnutrition;

2. Enabling families to take care of the rehabilitation of their children at home;

3. Preventing malnutrition among other children in the community now and in the future.

Children regularly screened in the communities are referred to Ambulatory Therapeutic Nutrition Units or FARNs according to their respective Severe Acute Malnutrition (SAM) or moderate status. The activities within the FARN take place in an internal session of 12 consecutive days, in an external session of 2 weeks and in monthly monitoring by weight. During the internal session, the mother / child couples take part daily in the culinary demonstration, the tasting and the awareness session. The external session is marked by the home visits made to these couples to follow the implementation of the lessons of the internal session. This step results in a weighing that corresponds to the 28th day since admission. At the end of this weighing, all the children who have gained a weight of 400 grams or more are discharged and are monitored monthly.

\subsection{Type of Study and Population Concerned}

This was a cross-sectional study that was conducted retrospectively and prospectively. The population studied consisted of children aged 6 to 59 months and their mothers.

\subsection{Sampling}

The communities that had benefited from the intervention for at least 3 months were selected to participate in the study.

There were seven such communities. To estimate the prevalence of malnutrition, we had two samples. The first consisted of all the children who had been screened for malnutrition at the beginning of the intervention (initial phase) in the 7 communities, we had a total of 1202 children. The second was an exhaustive sample of children in the communities in our survey (final phase), 746 children.

For monitoring the nutritional status of discharged children, the sample consisted of children who had left the FARN and had had at least 2 months of care in the community. We had a total of 147 children.

For the study of behavioral change in mothers in each of the 7 communities, 6 mothers were selected, 3 randomly selected from the FARN $(n=21)$ and 3 others who have never participated in the FARN and randomly selected from the list of community-based child screening $(n=21)$. We had a total of 42 mothers.

\subsection{Data Collection}

The data were gathered by four previously trained interviewers and divided into two binomials (one man and one woman).

The collection of anthropometric data was carried out retrospectively (initial phase) on the basis of the data obtained from the registers of the different FARNs and on the other, prospectively (final phase) by a field survey using the method door to door. Anthropometric measurements were taken using a Shakir or MUAC band and the age of the child was reported from the health record whenever possible or from the interview from the mother.

In order to monitor the nutritional status of discharged children, the collection of anthropometric data from the registers concerned the weighing of the 28th day, month 1 and month 2 in the community, as well as a new anthropometric measurement of the same children during the field survey for month 3 .

A questionnaire on knowledge and practices on breastfeeding, complementary feeding, care and hygiene was sent to mothers after their oral consent was obtained in order to assess their level of feeding behavior.

\subsection{Data Analysis}

The analysis of the data was carried out with the ENA software, specific for the processing of quantitative nutritional survey and mortality data. The nutritional 
indicator used to determine the prevalence of malnutrition and the different nutritional states was the Brachial Perimeter (BP). Thus, the child was reported to be moderately acutely malnourished for $\mathrm{BP}<125$ and $\mathrm{BP} \geq 115 \mathrm{~mm}$ or severely acute malnourished for $\mathrm{BP}<115 \mathrm{~mm}$ and / or with edema. Concerning food behavior data, they have been codified and analyzed using the software Excel. Each correct answer counted for 1 point and each bad answer was 0 points. Thus, for each practice, the score obtained in relation to the number of observations gave the performance index by category: (i) good if the investigation correctly answered more than $3 / 4$ of the questions either more than $75 \%$; (ii) fairly good if the number of correct answers was between 50 and $75 \%$; (iii) insufficient if the number of correct answers was less than $50 \%$. The test of Chi squared was used for the comparison of proportions. The significance level of the statistical tests used was set at $5 \%$.

\section{Results}

There was no significant difference between the samples of children who had been screened for initial and final malnutrition from the point of view of sex and age. Within each study sample there was a slight male predominance and children aged 6 to 17 months (Table 1).

Table 1. Characteristics by sex and age of samples of children who have been screened for malnutrition.

\begin{tabular}{llll}
\hline & Initial Phase & Final Phase & \\
& $\mathbf{N}=\mathbf{1 2 0 2}$ & $\mathbf{N}=\mathbf{7 4 6}$ & \\
\hline Sex & & & 0.898 \\
Male & $51.3 \%$ & $50.4 \%$ & \\
Female & $48.7 \%$ & $49.6 \%$ & \\
Age (months) & & & \\
$6-17$ & $27.5 \%$ & $39 \%$ & 0.118 \\
$18-29$ & $25.5 \%$ & $29.5 \%$ & \\
$30-41$ & $25.9 \%$ & $20 \%$ & \\
$42-59$ & $21.1 \%$ & $11.5 \%$ & \\
\hline
\end{tabular}

The prevalence of Global Acute Malnutrition (GAM) decreased by $3.5 \%$ (Table 2 ).

Table 2. Initial and final prevalence of acute malnutrition.

\begin{tabular}{llllll}
\hline & \multicolumn{2}{l}{ Initial Phase } & \multicolumn{2}{l}{ Final Phase } & \multirow{2}{*}{ Gap } \\
\cline { 1 - 4 } & $\mathbf{N}=\mathbf{1 2 0 2}$ & \multicolumn{2}{l}{$\mathbf{N}=\mathbf{7 4 6}$} \\
\hline n & $\mathbf{0}$ & $\mathbf{n}$ & $\mathbf{\%}$ & \\
\hline MAM & 21 & $1.7 \%$ & 06 & $0.8 \%$ & $0.9 \%$ \\
GAM & 97 & $8 \%$ & 40 & $5.4 \%$ & $2.6 \%$ \\
\hline
\end{tabular}

This malnutrition affects predominantly male children and those of the 6 to 17 months age group. This age group has the lowest rate of severe acute malnutrition in the final phase, $0 \%$ (Table 3).
Table 3. Distribution of types of acute malnutrition by sex and age according to phase.

\begin{tabular}{|c|c|c|c|c|}
\hline \multicolumn{5}{|c|}{ Initial Phase } \\
\hline & \multicolumn{2}{|c|}{ Moderate Acute Malnutrition } & \multicolumn{2}{|c|}{ Severe Acute Malnutrition } \\
\hline & $\mathbf{N}=97$ & $\%$ & $\mathbf{N}=\mathbf{2 1}$ & $\%$ \\
\hline \multicolumn{5}{|l|}{ Sex } \\
\hline Male & 50 & 51.5 & 10 & 47.6 \\
\hline Female & 47 & 48.4 & 11 & 52.3 \\
\hline \multicolumn{5}{|c|}{ Age (months) } \\
\hline $6-17$ & 54 & 55.6 & 13 & 61.9 \\
\hline $18-29$ & 34 & 35.0 & 5 & 23.8 \\
\hline $30-41$ & 5 & 5.1 & 3 & 14.8 \\
\hline $42-59$ & 4 & 4.1 & 0 & 0 \\
\hline
\end{tabular}

Table 3. Continued.

\begin{tabular}{|c|c|c|c|c|}
\hline \multicolumn{5}{|c|}{ Final Phase } \\
\hline & \multicolumn{2}{|c|}{ Moderate Acute Malnutrition } & \multicolumn{2}{|c|}{ Severe Acute Malnutrition } \\
\hline & $\mathbf{N}=\mathbf{4 0}$ & $\%$ & $\mathrm{~N}=06$ & $\%$ \\
\hline \multicolumn{5}{|l|}{ Sex } \\
\hline Male & 22 & 55 & 4 & 66.6 \\
\hline Female & 18 & 45 & 2 & 33.3 \\
\hline \multicolumn{5}{|c|}{ Age (months) } \\
\hline $6-17$ & 27 & 67.5 & 0 & 0 \\
\hline $18-29$ & 9 & 22.5 & 4 & 66.6 \\
\hline $30-41$ & 4 & 10 & 2 & 33.3 \\
\hline $42-59$ & 0 & 0 & 0 & 0 \\
\hline
\end{tabular}

Monitoring the nutritional status of discharged children showed a cure rate of $89.1 \%$ and a consolidation rate of this cure (good nutritional status) to $85.4 \%$ at 3 months. There is also an increase in the prevalence of moderate acute malnutrition from $10.9 \%$ to $12.9 \%$ and severe acute malnutrition from $0 \%$ to $2.41 \%$ (Figure 1 ).



Figure 1. Evolution of the nutritional status of discharged children.

There is a significant difference between the behavior of mothers receiving FARN and non-beneficiary mothers. The former have good feeding behavior compared to the latter (Table 4).

Table 4. Comparison of Good Feeding Behavior among Beneficiary and Non-Beneficiary FARN Mothers.

\begin{tabular}{lllll}
\hline \multirow{2}{*}{ Themes of feeding } & \multicolumn{2}{l}{ Beneficiary Mothers } & \multicolumn{2}{l}{$\begin{array}{l}\text { Non Beneficiary } \\
\text { Mothers }\end{array}$} \\
\cline { 2 - 5 } & $\mathbf{N = 2 1}$ & $\mathbf{\%}$ & $\mathbf{N = 2 1}$ & $\mathbf{\%}$ \\
\hline Breastfeeding practice & 17 & 80.95 & 15 & 71.4 \\
complementary feeding & 18 & 85.71 & 7 & 33.33 \\
Practice of care & 15 & 71.4 & 9 & 42.85 \\
Hygiene practice & 11 & 52.38 & 6 & 28.57 \\
\hline
\end{tabular}

$\mathrm{p}$-value $=0.0153$. 


\section{Discussion}

The similarity of the study samples indicates that these samples are actually from the same population. The predominance of the age group of 6 to 17 months reflects that of the general population of the region. This age group of 6 to 17 months was the most exposed because the risk of acute malnutrition is higher during the age of introduction of complementary foods and the weaning period which is often early and poorly adapted $[1,4]$, as shown in other studies. During this period of weaning between 12 and 24 months in Côte d'Ivoire, the children adapt poorly to the family dish, which is often neglected and poorly balanced. The vulnerability of children to infections at this time is very high and it is a period of high prevalence of malnutrition especially in its severe form [1]. Male children show a slight predominance of malnutrition compared to female children. This gender gap is also highlighted in some studies $[2,5,6]$. Overall, there was a decrease in the acute malnutrition rate from $9.7 \%$ to $6.2 \%$ in 6 months, either a $3.5 \%$ gap. The evaluation of a similar program at Save the Children in Sikasso, Mali, showed a reduction in the malnutrition rate in half after the implementation of the project over one year, from $41 \%$ to $28 \%$ of GAM [7]. Similarly in Senegal, Guinea and Mali, Basics II assessment found a decline in the prevalence rate of acute malnutrition in the beneficiary communities of this type of project compared to nonbeneficiary control communities $[8,9]$. In Benin, a similar program of community nutrition implemented in mono in 1998 and evaluated after 2 years of implementation showed a $13.0 \%$ reduction in the acute malnutrition rate [10]. Finally, in Kenya, a study on the Impact evaluation of positive deviance hearth in Migori County found the same evidence of reduced malnutrition. [11]. The results of our study and those of the above studies show that community programs to combat malnutrition such as FARN have a real impact on improving the nutritional status of children.

This decline in the malnutrition rate is more pronounced in the 6 to 17 month age group with a near-zero SAM rate. This result is linked to the good diffusion of the messages on breastfeeding and complementary feeding during the screening sessions. Improved knowledge of these practices has certainly contributed to this situation. The reduction in the prevalence of SAM from $1.7 \%$ to $0.8 \%$, or half, would be linked, on the one hand, to the screening and reference system developed by the FARN and on the other hand to the effectiveness of the support of Ambulatory Nutritional Units.

Moreover, the nutritional rehabilitation of children suffering from moderate acute malnutrition in the communities with the use of enriched local revenues is proving successful since the recommended weight gain of 400 grams to be discharged shows that among the discharged children there is a cure rate of more than $80 \%$. This rate of cure is much higher than that found by Philip James in an Ethiopian rural area [12] and at the minimum standard of $75 \%[13]$.

Of these discharged children, only $10.9 \%$ were still suffering from moderate acute malnutrition on the day of discharge. The FARN evaluations carried out in Mali and Guinea show cure rates that can be superposed to ours. They are respectively $74 \%, 80 \%$ to $90 \%$ of the children participating in the FARN [7, 8]. The follow-up in the community of discharged children shows a good consolidation of the nutritional status of children cured at 3 months. Respect for the attitudes of the center at home is a determining factor for this consolidation. The good nutritional status of discharged children with more than $80 \%$ cure having maintained a permanent state of healing shows the effectiveness of the activities of the management. However, the slight increase of malnutrition cases observed during the follow-up period reveals cases of relapse and non-cure. These cases of relapse and non-cure would be due to difficulties in accessing diversified foods in households to continue culinary demonstrations. A project by the NGO World Doctor in Niger shows this difficulty as an obstacle to this approach during its evaluation [14]. Regarding mothers' behavior in relation to food practices, there was a significant difference between those who benefited from FARN and non-beneficiaries. The beneficiary mothers have good feeding behavior than the others. This shows the capacity for change in terms of attitude and practical knowledge that FARN can generate in the community. This evolution in the knowledge and practices of the mothers participating in the FARN session activities has been confirmed by other studies $[6,7,8,9,15]$. However, deficiencies are noted in the practice of hygiene because hygiene support activities have not been integrated into this project, hence the low assimilation capacity and improvement of practices concerning this thematic. The good behavior observed in breastfeeding for both beneficiary mothers $(80.95 \%)$ and non-beneficiary mothers $(71.4 \%)$ was due in large part to numerous breastfeeding awareness campaigns held by the National Nutrition Program for the population, subsequently reinforced by the activities of the FARN. Furthermore, some mothers who did not take part in the activities of the centers in their communities improved some knowledge from the conversations with the mothers who participated in the homes.

\section{Conclusion}

The desire to consolidate the achievements of the management of malnutrition in health structures through the adoption of the FARN approach in Côte d'Ivoire is justified, given the favorable impact of this approach on the reduction of the rate of malnutrition and behaviors. Rapid extension of FARN to the entire territory appears to be essential today in view of a high national acute malnutrition rate estimated at more than $7 \%$ [16].

\section{References}

[1] Institut national de la Statistique (INS) (République de Côte d'Ivoire), ICF international, EDSCI III (2010-2012). Rapport préliminaire; juillet 2012. 
[2] Direction coordination programme national de nutrition DCPNN (République de Côte d'Ivoire), enquête nutritionnelle nationale basée sur la méthodologie SMART (juillet-aout 2012). Rapport final; septembre 2012.

[3] Ministère de la santé publique de Côte d'Ivoire, Document de Politique National de Nutrition; mars 2010.

[4] Azagoh-K R, Enoh Js, Niangue B, Cissé L, Oulai Sm, Andoh J. Connaissances et pratiques des mères d'enfants de 6 a 18 mois relatives a la conduite du sevrage: cas de l'hôpital général de Marcory. MALI MEDICAL 2013 TOME XXVIII $\mathrm{N}^{\circ} 4$.

[5] Abdon W. M. Mukalay et al., " Facteurs prédictifs de la malnutrition chez les enfants âgés de moins de cinq ans à Lubumbashi (RDC) », Santé Publique 2010/5 (Vol. 22), p. 541-550.

[6] Desalegne Amare, Birtukan Assefa, Ayenew Negesse, Birehanu Ayenie Baye Tsegaye. Prevalence of Undernutrition and Its Associated Factors among Children below Five Years of Age in Bure Town, West Gojjam Zone, Amhara National Regional State, Northwest Ethiopia. Advances in Public Health. Volume 2016, Article ID 7145708, 8 pages http://dx.doi.org/10.1155/2016/7145708.

[7] Save the children. Rapport d'activité sur la déviance positive en nutrition dans 8 villages de la zone de santé de Sikasso. Mali; 2001.

[8] Aïssatou WN, Serigne MD, Ismaïla T, Siaka K, et Djibril C. 2003. Stratégie de Réhabilitation Nutritionnelle à Base Communautaire par l'Approche de la Déviance Positive: Expériences de la Guinée, du Mali et du Sénégal. Publié par le Projet «Basic Support for Institutionalizing» (BASCIS II), Arligton, Va.

[9] Maslowsky et al. The Success of the Hearth Model in Guinea. Africare Food Security Review, No. 12, March 2008.
[10] Agueh VD, Makoutodé M, Dramaix M, Dujardin B, Hennart P. Effet de la participation à un programme de nutrition communautaire sur l'état nutritionnel des enfants au bénin. IRSP In: Rev Epidemiol Sante Publique, 2004, 52: 415-422.

[11] Otieno Calvince Anino, Gertrude Mercy Were, Jennifer Wanjiku Khamasi. Impact evaluation of positive deviance hearth in Migori County, Kenya. African Journal of Food, Agriculture, Nutrition and Development. Vol 15, №5 (2015).

[12] James P, Sadler K, Wondafrash M, Argaw A, Luo H, Geleta B, et al. (2016) Children with Moderate Acute Malnutrition with No Access to Supplementary Feeding Programmes Experience High Rates of Deterioration and No Improvement: Results from a Prospective Cohort Study in Rural Ethiopia. PLoS ONE 11 (4): e0153530. doi:10.1371/ journal. pone. 0153530 .

[13] Minimum Standards in Food Security and Nutrition: The Sphere Handbook. Available from:

http://www.spherehandbook.org/en/management-of-acutemalnutrition-and-micronutrient-deficiencies-standard-1moderate-acute-malnutrition/ [Last accessed on 2017 Nov 25].

[14] Magali B. Projet de recherche Action plaidoyer Niger Médecin du Monde. Rapport mission évaluation interne S2AP. Février 2010: 16-18.

[15] Marion L. Roche, Grace S. Marquis, Theresa W. Gyorkos, Brittany Blouin, Julieta Sarsoza, Harriet V. Kuhnlein. A Community-Based Positive Deviance/Hearth Infant and Young Child Nutrition Intervention in Ecuador Improved Diet and Reduced Underweight, Journal of Nutrition Education and Behavior. 2017, Volume 49, Issue 3, Pages 196-203.

[16] MSLS, INS (Ministère de la Santé et de la Lutte contre le Sida et Institut National de la Statistique). 2012. Enquête de Démographie et Santé et à Indicateurs Multiple. Abidjan: s.n., 2012. 